\title{
Ventilatory care in status asthmaticus
}

\author{
Robert J Smyth MD FRCPC \\ Department of Anaesthesia, York County Hospital, Newmarket, Ontario
}

\section{RJ Smyth. Ventilatory care in status asthmaticus. Can Respir J 1998;5(6):485-490.}

Asthma continues to pose a significant medical problem in terms of both morbidity and mortality. A number of patients with a severe exacerbation of asthma fail medical therapy and require urgent intubation and mechanical ventilation. New modalities of ventilatory support, including noninvasive ventilation, have been shown to provide effective ventilation even in the presence of severe bronchoconstriction. An intrinsically high level of auto positive end-expiratory pressure in these patients requires a precise balance between respiratory frequency, tidal volume and inspiratory flow rates. Pressure support ventilation reduces the risk of barotrauma and lowers the work of breathing in these patients. Adjuvant therapy with inhaled anesthetics and bronchoalveolar lavage may also be indicated in patients requiring high pressures to achieve adequate ventilation.

Key Words: Asthma, Auto PEEP, Intubation, Mechanical ventilation, Noninvasive ventilation, Pressure support

\section{Les soins ventilatoires en cas de mal asthma- tique}

RÉSUMÉ : L'asthme continue de représenter un problème médical important sur le plan de la morbidité et de la mortalité. Certains patients souffrant d'une grave exacerbation de l'asthme ne réagissent pas à la pharmacothérapie et doivent être intubés d'urgence et recevoir une ventilation mécanique. Il est démontré que de nouvelles modalités de soutien ventilatoire, y compris la ventilation non effractive, sont efficaces même en cas de bronchoconstriction prononcée. Pour obtenir un taux intrinsèque élevé de pression autopositive en fin d'expiration, il faut obtenir un équilibre délicat de la fréquence respiratoire, du volume courant et du débit inspiratoire. La ventilation assistée par pression réduit le risque de barotraumatisme ainsi que le travail respiratoire de ces patients. Un traitement d'appoint aux anesthésiques par inhalation et un lavage bronchoalvéolaire peuvent également être recommandés dans le cas des patients qui ont besoin d'une pression élevée pour parvenir à une ventilation convenable.
$\mathrm{D}$ espite early and aggressive treatment, patients in status asthmaticus (SA) have high morbidity and mortality rates, which continue to pose a major medical problem. Mortality rates in asthma have been steadily increasing in many parts of the world. Canadian data show that approximately 90,000 asthmatic patients are admitted to hospital each year, and 400 to 500 of these patients will die of the disease (1). The rise in mortality rates worldwide appears to be multifactorial; however, some investigators feel that undertreatment in the acute phase may be largely responsible (2).

Unfortunately, many asthmatic patients who seek medical attention have been experiencing worsening symptoms for several days and relying increasingly on inhaled bronchodilators. A subgroup of patients in SA will progress rapidly to the sudden asphyxic asthma, and early identification of these patients remains difficult. It has been shown that these patients have intrinsically low levels of eosinophils in airway submucosa (3) and reduced intraluminal mucous (4). Increased airway resistance results in both inspiratory and expiratory obstruction, pulmonary hyperinflation and high levels of intrinsic or 'auto' positive end-expiratory pressure (PEEP) (5). During acute exacerbations, reductions in forced expiratory volume in $1 \mathrm{~s}\left(\mathrm{FEV}_{1}\right)$ of more than $50 \%$ of baseline values have been associated with a 10 -fold increase in the work of breathing (6). Irrespective of the pathogenesis of 
symptoms, any asthmatic patient presenting with respiratory distress is at significant risk of impending respiratory failure and death. This paper describes the treatment modalities available for patients in SA who require ventilatory support during the acute phase of their disease.

\section{NONINVASIVE VENTILATION}

Noninvasive ventilation (NIV) consists of intermittent positive pressure ventilation through a face mask with the patient in the upright position, with or without continuous positive airway pressure (CPAP). Noninvasive mask ventilation has been used to improve alveolar ventilation, obviating the need for endotracheal intubation. It does not protect against aspiration or gastric insufflation, but does reduce the need for sedation and muscle paralysis. Several reports have shown an improvement in gas exchange with NIV in acute respiratory failure $(7,8)$. Meduri et al $(9)$ reported on a population of 17 asthmatic patients who were admitted to the intensive care unit and received noninvasive positive pressure ventilation (NPPV). Respiratory acidosis was present in all patients on admission (pH 7.25 $\pm 0.07, P_{2} \mathrm{CO}_{2} 65 \pm 11 \mathrm{mmHg}$ ), and eight of the 17 patients had been intubated for respiratory failure on previous admissions. Patients were ventilated through a face mask in synchrony with spontaneous respirations with added pressure support ventilation (PSV) to give an exhaled tidal volume greater than $7 \mathrm{~mL} / \mathrm{kg}$ and CPAP of three to five $\mathrm{cm}$ $\mathrm{H}_{2} \mathrm{O}$. Pressure support was adjusted to achieve a respiratory rate of greater than 25 breaths/min and patient comfort. The mean duration of NPPV was $16 \mathrm{~h}$, and there were no complications in this group. Only two of the 17 patients required subsequent intubation for worsening hypercapnia.

NIV appears to be an acceptable alternative approach for short term ventilatory support in asthmatic patients, although more experience with this mode of ventilation is required before NIV becomes standard therapy in SA. This mode of ventilation may not be appropriate for the severely dyspneic patient or, obtunded or obese patients who are at high risk of aspiration. Similarly, claustrophobic patients may not be able to tolerate the face mask, even for short periods of time. It may, however, provide support while pharmacological therapy takes effect and, thus, eliminate the complications associated with endotracheal intubation.

\section{INTUBATION}

The decision to intubate patients in SA is made on the basis of clinical deterioration. Intubation should be considered for the patient who is severely dyspneic, has altered mental status and/or an inability to protect the airway. An increasing arterial $\mathrm{PCO}_{2}$ is an ominous sign and develops when the $\mathrm{FEV}_{1}$ is less than $25 \%$ of age-predicted values (10). Patients who develop hypercapnia in the presence of clinical deterioration are in urgent need of ventilatory support, although hypercapnia $\left(\mathrm{PCO}_{2}>40 \mathrm{mmHg}\right)$ alone may not be an indication for intubation. Intubation and ventilation is not an innocuous procedure, and has been associated with significant morbidity and mortality (11). Zimmerman et al (12) reported that one or more complications occurred in $46 \%$ of intubated asthmatic patients. More than one-third of all complications occurred during intubation and $47 \%$ during the intensive care unit stay. Difficult and esophageal intubations were encountered in $15.7 \%$ of all patients, which emphasizes the need for experienced personnel in the management of these potentially difficult airways.

The method of securing the airway depends on the level of obtundation, presence of a full stomach and anatomical features, such as prominent incisors, short neck and reduced mobility of the temporomandibular joint. Most clinicians favour the use of oral intubation in the obtunded or severely dyspneic patient. In the spontaneously breathing patient, nasotracheal intubation, either blind or with the aid of a fiberoptic bronchoscope, may be considered. Complications of nasotracheal intubation include esophageal intubation, nasal trauma, sinusitis and bleeding, which may limit the usefulness of this approach. Nasotracheal tubes are usually better tolerated in prolonged ventilation, but care must be taken to avoid alar necrosis due to traction on the nasotracheal tube. Oral intubation in a conscious patient may require the use of sedation or paralysis to facilitate easy airway access and an optimal view of the glottis. In the obtunded or cooperative patient, the airway may be sprayed with lidocaine aerosol to minimize gagging and discomfort. Sedation may be achieved with short acting benzodiazepines, such as midazolam, a water soluble agent with a potency two to three times that of diazepam. The elimination half-time ( 1 to $4 \mathrm{~h}$ ) is also shorter than diazepam and, thus, provides a rapid, smooth recovery. In carefully titrated doses ( $1 \mathrm{mg}$ to $2 \mathrm{mg}$ every two to three mins), midazolam provides effective sedation with minimal hemodynamic disturbance. Morphine, even in small doses (1 $\mathrm{mg}$ to $2 \mathrm{mg}$ ), may result in hypotension and bronchoconstriction due to histamine release. Propofol, a nonbarbiturate hypnotic and anaesthetic drug, may cause significant hypotension because it reduces systemic vascular resistance. There is no change in plasma histamine levels following injection of propofol. If used for sedation, this drug must be used with caution because of the risk of profound respiratory depression, especially in the presence of opioids. Ketamine, a phencyclidine derivative, increases central sympathetic drive (13) in addition to increasing the plasma concentrations of both epinephrine and norepinephrine (14). Upper airway reflexes remain intact, and bronchodilation results from its sympathomimetic properties. Ketamine elicits a dissociative state in which the eyes remain open with a slow nystagmic gaze, and both amnestic and analgesic properties are intense. In doses of $1 \mathrm{mg}$ to $2 \mathrm{mg} / \mathrm{kg}$, ketamine may provide adequate sedation for intubation. Should trismus or agitation prevent access to the airway, muscle paralysis with succinylcholine $(1 \mathrm{mg} / \mathrm{kg})$ may be necessary. Protection against regurgitation and aspiration before the onset of muscle relaxation is afforded by cricoid pressure (firm downward pressure on the cricoid cartilage) until confirmation of the endotracheal tube in the trachea and inflation of the cuff.

Management of the airway in an awake, struggling, hypoxemic patient can be stressful and carries an extremely high potential for mishap. Careful preparation is imperative 
and the pneumonic 'MIDSOLES' summarizes the equipment necessary for airway management (Table 1).

If possible, the airway should be secured with either a blind nasal or oral approach using a minimum of sedation. Preference of nasal versus oral approach depends on the degree of familiarity with each technique and the presence of trismus, which necessitates a nasal approach to the airway. One method uses topical anesthesia to the upper airway with aerosolized lidocaine followed by intravenous sedation with ketamine $1 \mathrm{mg} / \mathrm{kg}$. Oxygen should be applied to the patient's face with a resuscitation bag-mask (Laerdal Company), which ensures $90 \%$ to $100 \%$ inspired oxygen. Muscle paralysis should only be considered in the case of extreme trismuser/agitation and should be administered by a physician familiar with the use of these drugs.

\section{MUSCLE PARALYSIS}

To optimize chest wall compliance and reduce peak inspiratory pressure, muscle paralysis has been used during mechanical ventilation. Some investigators feel that following intubation, the respiratory muscles should be rested with paralysis (11). However, Griffin et al (15) described an acute myopathy that developed after prolonged paralysis with nondepolarizing muscle blockade in three asthmatic patients. The patients had received either pancuronium or vecuronium for 10 to 14 days, in addition to moderate doses of corticosteroids (methylprenisolone $320 \mathrm{mg}$ to $750 \mathrm{mg} /$ day). Weaning all three patients from these drugs was difficult because of proximal and distal muscle weakness. Muscle biopsies consistently showed muscle necrosis and degeneration of both the type 1 and type 2 muscle fibers. Elevated levels of creatine kinase (CK) and myoglobinuria were also reported in one patient. This is in contrast to steroid myopathy, which primarily involves the proximal muscles with a normal CK (16). The steroid structure of both pancuronium and vecuronium is believed to interact with corticosteroids (17). Prolonged muscle paralysis results in a 'denervated state' (18), in which the muscle develops an increased number of steroid receptors (19). This may help to explain the additive effect of neuromuscular blockers and corticosteroids in the development of myopathies in these patients. Atracurium besylate, a nonsteroidal, nondepolarizing muscle relaxant, has also been shown to result in prolonged muscle weakness. Tousignant et al (20) reported onset of acute quadriparesis in an 18-yearold asthmatic patient after seven days of therapy with atracurium and methylprednisolone. At that time, electrical nerve stimulation monitoring indicated full return of neuromuscular function. No muscle biopsy was performed, but electrophysiological studies showed evidence of denervation and $\mathrm{CK}$ had risen from admission levels of $112 \mathrm{U} / \mathrm{L}$ to $763 \mathrm{U} / \mathrm{L}$. Hoey et al (21) reported similar findings in two patients treated with corticosteroids and atracurium. Electromyography showed changes identical to those described earlier. One case report also described muscle paralysis persisting for 50 $\mathrm{h}$ after discontinuation of atracurium in a patient who did not receive corticosteroids (22). Therefore, it appears that prolonged muscle weakness may result following the use of

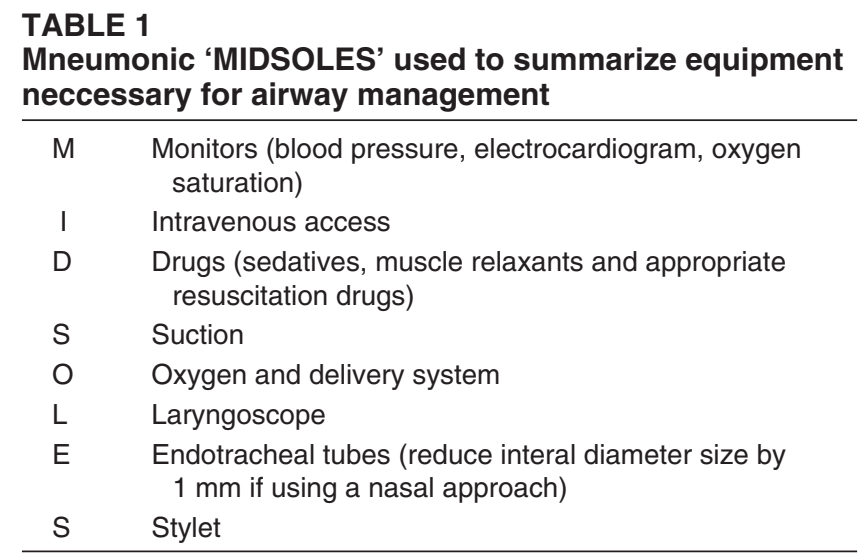

various nondepolarizing muscle relaxants and that the molecular structure may not be the only contributing factor. The association with concomitant corticosteroid use is not well defined. Routine neuromuscular monitoring should be employed in all patients receiving muscle relaxants, and drug dosages should be titrated to elicit a visible response to the electrical nerve stimulation. Newer modes of ventilation (NIV and PSV) may eliminate the need for muscle relaxation and reduce the risks associated with prolonged muscle paralysis.

\section{MECHANICAL VENTILATION}

The aim of mechanical ventilation in asthmatic patients is to decrease the work of breathing, maintain adequate oxygenation and augment alveolar ventilation in the face of airway edema, anddiffuse mucous plugging of the small airways. Mechanical ventilation is not an innocuous procedure and has been associated with significant morbidity and mortality (11). The ability to achieve adequate alveolar ventilation is difficult due to the intrinsically high airway pressures and the need for a prolonged expiratory phase. Strategies such as permissive hypercapnia and reduced inspiratory to expiratory (I:E) ratio may help minimize lung hyperinflation. Other methods used to prolong expiratory time include reductions in respiratory rate, decreasing tidal volume, increasing inspiratory flow rate (decreases inspiratory time) and using a square wave flow pattern. Tuxen and Lane (23) showed that by increasing ventilation from 10 $\mathrm{L} / \mathrm{min}$ to $26 \mathrm{~L} / \mathrm{min}$ end-expiratory lung volume was increased by a factor of three to four times. This could be partially offset by increasing the inspiratory flow rate, but expiratory time was significantly shortened and lung hyperinflation still occurred. They found that the most important variables in minimizing hyperinflation were a low minute volume, high inspiratory flow rates and a low tidal volume (Figure 1).

Certain lung units may require a long expiratory time due to mucous plugging and bronchial wall edema. As a result, the lung becomes hyperinflated with an increased risk of barotrauma and hypotension. In the presence of dynamic lung hyperinflation, this is a positive pressure at end-expiration 


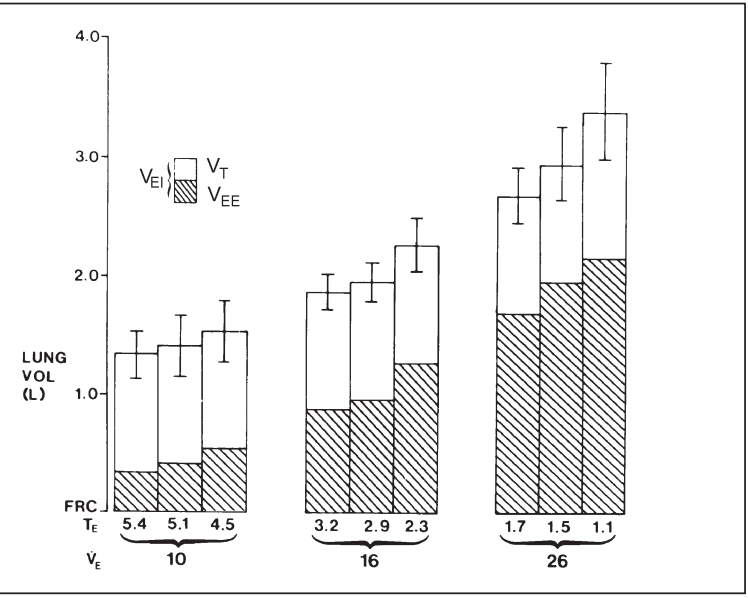

Figure 1) Patients with status asthmaticus were ventilated using three inspiratory flow rates $(100 \mathrm{~L} / \mathrm{min}, 70 \mathrm{~L} / \mathrm{min}$ and $40 \mathrm{~L} / \mathrm{min}$ ) during three different levels of minute ventilation $(10 \mathrm{~L} / \mathrm{min}$, $16 \mathrm{~L} / \mathrm{min}$ and $26 \mathrm{~L} / \mathrm{min}$ ). Low inspiratory flow rates at constant tidal volume shortened expiratory time and resulted in lung hyperinflation (increased end inspiratory volume). Hyperinflation was most pronounced with low inspiratory flow rates and high minute ventilation. VE Minute ventilation; VEE End expiratory volume; TE Expiratory time; VT Tidal volume. Reproduced with permission from reference 23

so-called auto-PEEP (24). Auto-PEEP has been shown to increase the work of breathing by several mechanisms. The lung operating on a flatter portion of the pressure-volume curve requiring greater swings in intrathoracic pressures for a given change in lung volume, and the chest wall is on a more noncompliant portion of the pressure-volume curve and more resistant to outward movement. This becomes most evident in lung units with long time constants (volume of a lung unit/flow rate into it) and may also increase alveolar dead space if alveolar pressure exceeds perfusion pressure. Auto-PEEP has typically been measured by occluding the expiratory valve at end-expiration, thus allowing alveolar pressure to equilibrate with proximal airway pressure (Figure 2 ). In the ventilated patient, lung hyperinflation may reduce venous return when intrathoracic pressure exceeds pulmonary venous pressure. During hyperinflation, delivery of mechanical breaths may become difficult and result in higher peak airway pressure, diminished breath sounds, and jugular venous distension may become evident.

Leatherman and Ravenscraft (25) showed that measurement of auto-PEEP may significantly underestimate the degree of lung hyperinflation due to widespread airway closure at end-expiration. Measured auto-PEEP only assesses endexpiratory pressure define Palv in communicating airways and is basically an estimate of the average end-expiratory Palv in the communicating airways. The efficacy of externally applied PEEP during mechanical ventilation of asthmatic patients remains an issue for debate (26). Qvist et al (26) employed high levels of PEEP (up to $25 \mathrm{~cm} \mathrm{H}_{2} \mathrm{O}$ ) in two asthmatic patients in an attempt to open closed lung units.

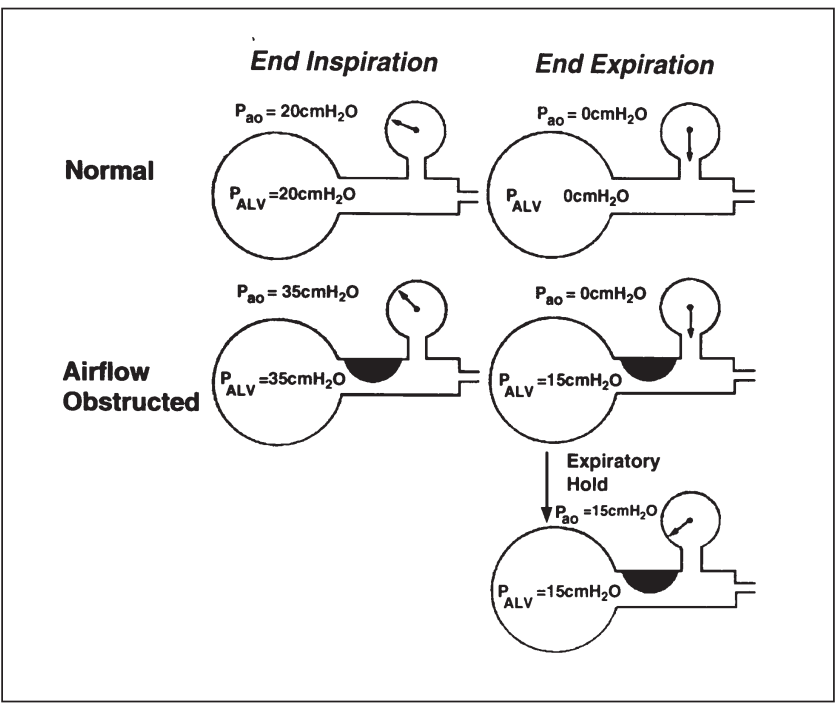

Figure 2) Under normal conditions airway opening pressure $\left(\mathrm{P}_{a o}\right)$ equals alveolar pressure ( $\mathrm{Palv})$ and atmospheric pressure at end expiration. In the obstructed airway $\mathrm{Palv}$ is increased at end inspiration due to gas trapping (increased auto positive end-expiratory pressure [auto-PEEP]). At end expiration $\mathrm{P} a l v>\mathrm{P}_{a o}$ and airway flow will continue around the obstruction. After an expiratory hold manoeuvre $\mathrm{P}_{a o}$ will increase until it equals $\mathrm{Palv}$. This provides a measurement of auto-PEEP). Reproduced with permission from reference 25

There was marked reduction in peak airway pressure and improved arterial oxygenation. Marini (27) states that hyperinflation and, therefore, flow limitation may be improved by adding low levels of PEEP (less than $8 \mathrm{~cm} \mathrm{H}_{2} \mathrm{O}$ ), which may redefine the anatomical location of airway compression. This would allow narrowed or collapsed airways to expand without increasing Palv. However, Tuxen et al (28) warn that PEEP greater than $5 \mathrm{~cm} \mathrm{H}_{2} \mathrm{O}$ may increase end-expiratory lung volume and compromise venous return.

PSV provides a therapeutic alternative to controlled ventilation in asthmatic patients that reduces the risk of barotrauma secondary to high inspiratory pressures. With this mode of ventilation, the spontaneously breathing patient sets his or her own respiratory rate, tidal volume and I:E ratio. Augmented inspiratory flow initiated by negative inspiratory pressure $\left(-1\right.$ to $\left.-2 \mathrm{~cm} \mathrm{H}_{2} \mathrm{O}\right)$ decreases the work of breathing by unloading the respiratory muscles $(29,30)$ and by reducing the work required to overcome the resistance provided by the breathing circuit and endotracheal tube (31). The proper level of respiratory muscle unloading with pressure support may also promote muscle reconditioning and prevent muscle fatigue. Tokioka et al (33) studied six patients with SA using both PSV and assist-controlled ventilation (ACV) at minute intervals. They found that as inspiratory flow was increased with PSV, tidal volume increased and respiratory rates were reduced. There were no differences in the oxygen cost of breathing (estimated from oxygen consumption), tidal volume or minute ventilation. Peak airway pressures, however, were $40 \%$ lower with PSV ( $30 \pm 10 \mathrm{~cm} \mathrm{H}_{2} \mathrm{O}$ PSV, $50 \pm 13 \mathrm{ACV}$ ) at comparable tidal vol- 
umes of $10 \mathrm{~mL} / \mathrm{kg}$. Respiratory muscles are allowed to assist in exhalation enabling better lung emptying. In the presence of hyperinflation, the elastic recoil forces become impaired due to overstretching of the lung, accentuating gas trapping and alveolar hypoventilation. By decreasing the inspiratory work of breathing, PSV reduces muscle fatigue and improves patient assisted ventilation (33). In the SA lung, hyperinflation may still occur with PSV; however, by optimizing tidal volume dangerous levels of hyperinflation are avoided.

Banner et al (34) describe a technique for setting optimal levels of PSV using intrapleural (esophageal) pressure recordings. Inspiratory work of breathing is reflected in large swings in intrapleural pressure. As PSV is increased, esophageal pressure will decline until it reaches a nadir at $\mathrm{PSV}_{\max }$. Further increases in PSV will not reduce esophageal pressure. At this point, the work of lung inflation is essentially zero, and the respiratory muscles have to work only to provide the small amount of inflation associated with chest wall expansion.

\section{ADJUVANT THERAPY FOR THE INTUBATED PATIENT}

Inhaled anaesthetics: Tracheal intubation and mechanical ventilation are used to improve alveolar ventilation, and aggressive adjuvant therapy is often required to optimize bronchodilation. In cases of refractory hypoxemia with or without hypercapnia, inhaled anaesthetics may improve oxygenation and ventilation, while allowing time for pharmacological therapy to reduce airway inflammation. Volatile anaesthetic agents have been used in the intensive care setting to facilitate sedation and improve gas exchange through their powerful bronchodilatory properties. Inhalational agents from both the alkane (halothane) and ether (isoflurane, ethrane) groups have unique physical and chemical properties producing reductions in airway resistance in a dose-dependent manner (35). Early reports described the use of cyclopropane and tribromethanol in the treatment of severe bronchial asthma (36,37); and more recently, authors cited a beneficial role of halothane in SA (38). Halothane has a direct inhibitory effect on bronchial smooth muscle, probably through reduction in

\section{REFERENCES}

1. Hogg RS, Schechter MT, Montaner JSG, et al. Asthma mortality in Canada, 1946 to 1990. Can Respir J 1995;2:61-6.

2. Molfino N, Nannini LJ, Martelli AN, Slutsky AS. Respiratory arrest in near-fatal asthma. N Engl J Med 1991;324:285-8.

3. Sur S, Crotty TB, Kephart GM, et al. Sudden-onset fatal asthma. A distinct clinical entity with few eosinophils and relatively more neutrophils in the airway submucosa. Am Rev Respir Dis 1993;148:713-9.

4. Reid LM. The presence or absence of bronchial mucus in fatal asthma. J Allergy Clin Immunol 1987;80:415-6.

5. Maltais F, Sovilj M, Goldberg P, Gottfried SB. Respiratory mechanics in status asthmaticus. Chest 1994;106:1401-6.

6. Martin JG, Shore SA, Engel LA. Mechanical load and inspiratory muscle action during induced asthma. Am Rev Respir Dis 1983;128:455-60.

7. Meduri GU. Noninvasive positive-pressure ventilation in patients with acute respiratory failure. Clin Chest Med 1996;17:513-53.

8. Meduri GU, Abou-Shala N, Fox RC, Jones CB, Leeper RV, Wunderink RG. Noninvasive face mask mechanical ventilation vagal tone (39). Halothane also sensitizes the myocardium to circulating catecholamines, producing ventricular arrhythmias. The dosage of submucosally administered epinephrine that produced ventricular arrhythmias in $50 \%$ of patients was $2.1,6.7$ and $10.9 \mu \mathrm{g} / \mathrm{kg}$ for halothane, isoflurane and ethrane, respectively (40). The threshold dose of epinephrine causing ventricular arrhythmias during sevoflurane anaesthesia is 5 $\mu \mathrm{g} / \mathrm{kg}$ (41). Children are able to tolerate larger doses of epinephrine under halothane anesthesia compared with adults (10 $\mu \mathrm{g} / \mathrm{kg}$ versus $7.8 \mu \mathrm{g} / \mathrm{kg}$ ) (40). Administration of anaesthetic agents is not a common procedure in the intensive care unit; however, Sullivan and Robbins (42) described a delivery system that is easily attached to an intensive care unit ventilator enabling delivery of isoflurane.

Bronchoscopy and alveolar lavage: Despite aggressive chest physiotherapy, hydration and bronchodilator administration, mucous impaction of small airways may persist and limit optimal gas exchange. Earlier reports described the use of bronchoscopy and saline lavage in SA. Henke et al (43) presented a case using bronchoscopy and instillation of acetylcysteine (20\%) and albuterol into selective airways over several days. Dissolution of the mucous plugs became clinically apparent with improved gas exchange, reduced peak airway pressures and lower auto-PEEP. In addition to its mucolytic properties, acetylcysteine is a powerful bronchoconstrictor that requires the addition of a bronchodilating agent. The presence of a pediatric bronchoscope into the lumen of an adult endotracheal tube ( $8 \mathrm{~mm}$ or larger) will cause a transient elevation in airway pressure, but this may be offset by manual positive pressure ventilation with increased flow rates. An adult bronchoscope (outer diameter $4.8 \mathrm{~mm}$ or larger) may further increase expiratory resistance and lead to dangerous levels of hyperinflation. Suction of mucous plugs may be difficult through a pediatric bronchoscope, and direct suction on the airways may result in airway collapse and hypoxemia. To minimize these effects, Henke et al (43) performed daily lavage on separate lobes of the lung. Bronchoscopy and lavage, however, have not been accepted as standard therapy for ventilated SA patients. Larger studies in this patient population need to be undertaken to evaluate the safety and effectiveness of this therapy.

inpatients with acute hypercapnic respiratory failure. Chest 1991;100:445-54

9. Meduri GU, Cook TR, Turner RE, Cohen M, Leeper RV. Noninvasive positive pressure ventilation in status asthmaticus. Chest 1996;110:767-74.

10. Nowak RM, Tomlanovich MC, Sarkar DD, Kvale PA, Anderson JA. Arterial blood gases and pulmonary function testing in acute bronchial asthma. Predicting patient outcomes. JAMA 1983;249:2043-6.

11. Mansel JK, Stogner SW, Petrini M, Norman JR. Mechanical ventilation in patients with acute severe asthma. Am J Med 1990;89:42-8.

12. Zimmerman JL, Dellinger RP, Shah AN, Taylor RW. Endotracheal intubation and mechanical ventilation in severe asthma. Crit Care Med 1993;21:1727-30.

13. Wong DHW, Jenkins LC. An experimental study of the mechanism of action of ketamine on the central nervous system. Can Anaesth Soc J 1974;21:57-67.

14. Baraka A, Harrison T, Kachachi T. Catecholamine levels after ketamine anesthesia in man. Anesth Analg 1973;52:198-200. 
15. Griffin D, Fairman N, Coursin D, Rawsthorne L, Grossman JE. Acute myopathy during treatment of status asthmaticus with corticosteroids and steroidal muscle relaxants. Chest 1992;102:510-4.

16. Layzer R. Neuromuscular Manifestations of Systemic Disease. Philadephia: FA Davis, 1985:101-4.

17. Kaplan PW, Rocha W, Sanders DB, D’Souza B, Spock A. Acute steroid-induced tetraplegia following status asthmaticus. Pediatrics 1986;78:121-3.

18. Drachman D, Stanley E, Pestronk A. Neural regulation of muscle roperties. In: Serrantrice G, et al, eds. Neuromuscular Diseases. New York: Raven Press, 1984:415-22.

19. DuBois DC, Almon RR. A possible role for glucocorticoids in denervation atrophy. Muscle Nerve 1981;4:370-3.

20. Tousignant CP, Bevan DR, Eisen AA, Fenwick JC, Tweedale MG. Acute quadriparesis in an asthmatic treated with atracurium. Can J Anaesth 1995;42:224-7.

21. Hoey LL, Joslin SM, Nahum A, Vance-Bryan K. Prolonged neuromuscular blockade in two critically ill patients treated with atracurium. Pharmacotherapy 1995;15:254-9.

22. Rubio ER, Seelig CB. Persistent paralysis after prolonged use of atracurium in the absence of corticosteroids. South Med J 1996;89:624-6.

23. Tuxen DV, Lane S. The effects of ventilatory pattern on hyperinflation, airway pressures and circulation in mechanical ventilation of patients with severe airflow obstruction. Am Rev Respir Dis 1987;136:872-9.

24. Pepe P, Marini JJ. Occult positive end-expiratory pressure in mechanically ventilated patients with airflow obstruction. Am Rev Respir Dis 1982;126:166-70.

25. Leatherman JW, Ravenscraft SA. Low measured auto-positive end-expiratory pressure during mechanical ventilation of patients with severe asthma: hidden auto-positive end-expiratory pressure. Crit Care Med 1996;24:541-6.

26. Qvist J, Andersen JB, Pemberton M, Bennike KA. High-level PEEP in severe asthma. N Engl J Med 1982;307:1347-8

27. Marini JJ. Should PEEP be used in airflow obstruction? Am Rev Respir Dis 1989;140:1-3.

28. Tuxen DV, Williams TJ, Scheinkestel CD, Czarny D, Bowes G. Use of a measurement of pulmonary hyperinflation to control the level of mechanical ventilation in patients with acute severe asthma. Am Rev Respir Dis 1992;146:1136-42.

29. Van de Graaff WB, Gordey K, Dornseif SE, et al. Pressure support.
Changes in ventilatory pattern and components of the work of breathing. Chest 1991;100:1082-9.

30. Cohen IL, Bilen Z, Krishnamurthy S. The effects of ventilator working pressure during pressure support ventilation. Chest 1993;103:588-92.

31. Kacmarek RM. The role of pressure support ventilation in decreasing work of breathing. Respir Care 1988;33:99-120.

32. Tokioka H, Saito S, Takahashi T, et al. Effectiveness of pressure support ventilation for mechanical ventilatory support in patients with status asthmaticus. Acta Anaesthiol Scand 1992;36:5-9.

33. Tokioka H, Saito S, Saeki S, Kinjo M, Kosaka F. The effect of pressure support ventilation on auto-PEEP in a patient with asthma. Chest 1992;101:285-6.

34. Banner JB, Kirby RK, MacIntyre NR. Patient and ventilator work of breathing and ventilatory muscle loads at different levels of pressure support ventilation. Chest 1991;100:531-3.

35. Hirshman CA, Edelstein G, Peetz S, Wayne R, Downes H. Mechanism of action of inhalational anesthesia on airways. Anesthesiology 1982;56:107-11.

36. Meyer NE, Schotz S. The relief of severe intractable bronchial asthma with cyclopropane anesthesia. J Allergy 1938;10:239.

37. Fuchs AM. The interruption of the asthmatic crisis by tribromethanol (Avertin). J Allergy 1937;8:340.

38. Colaco C, Crago R, Weisbert A. Halothane for status asthmaticus in the intensive care unit - a case report. Can Anaesth Soc J 1978;25:329-30.

39. Tobias JD, Hirshman C. Attenuation of histamine induced airway constriction by albuterol during halothane anesthesia. Anesthesiology 1990;72:105-10.

40. Johnston RR, Eger EI, Wilson C. A comparative interaction of epinephrine with enflurane, isoflurane and halothane in man. Anesth Analg 1976;55:709-12.

41. Navarro R, Weiskopf RB, Moore MA, et al. Humans anesthetized with sevoflurane or isoflurane have similar arrhythmic response to epinephrine. Anesthesiology 1994;80:545-9.

42. Sullivan M, Robbins K. Adaptation of an ICU ventilator to deliver isoflurane. Can J Anaesth 1995;42:841-2.

43. Henke CA, Hertz M, Gustafson P. Combined bronchoscopy and mucolytic therapy for patients with severe refractory status asthmaticus on mechanical ventilation: a case report and review of the literature. Crit Care Med 1994;22:1880-3 


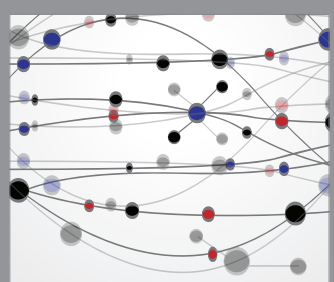

The Scientific World Journal
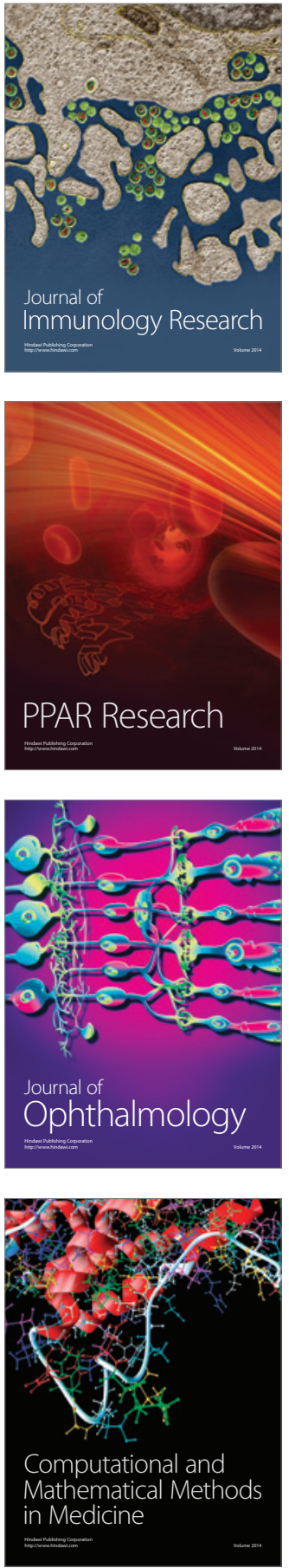

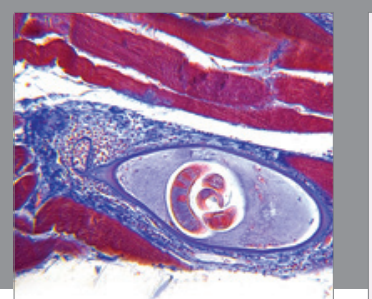

Gastroenterology Research and Practice

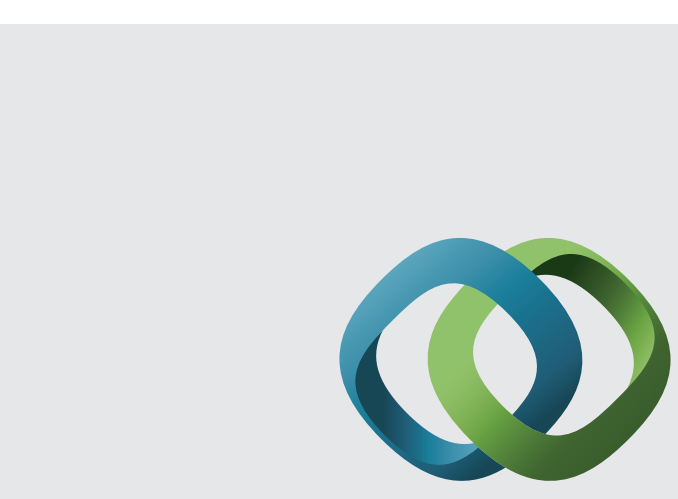

\section{Hindawi}

Submit your manuscripts at

http://www.hindawi.com
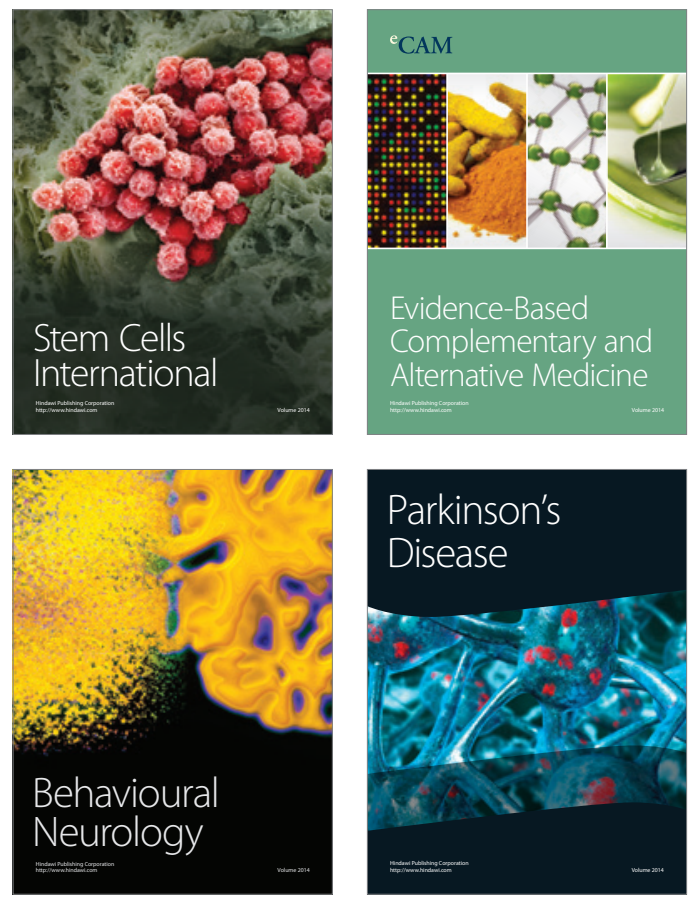
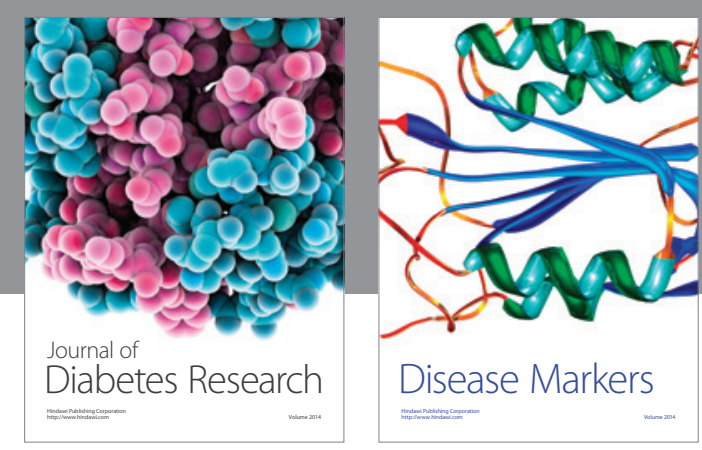

Disease Markers
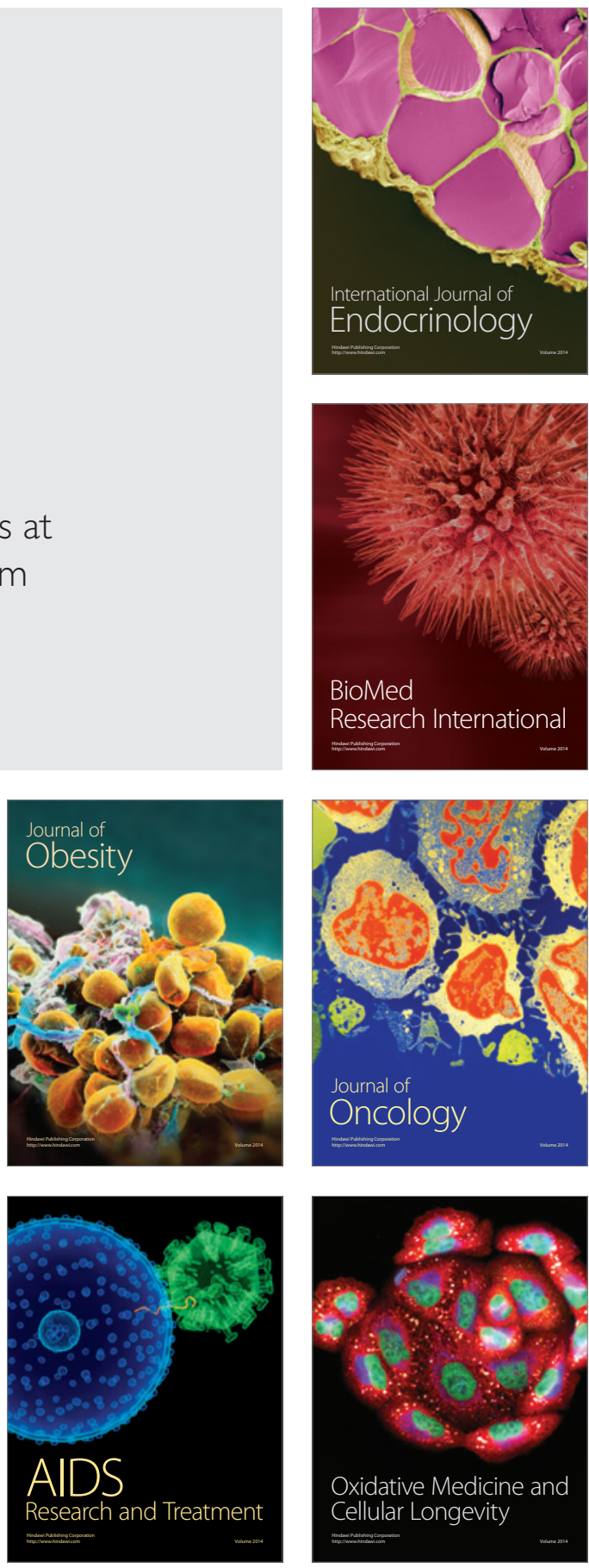